\title{
HIV and partner violence: Implications for HIV voluntary counseling and testing programs in Dar es Salaam, Tanzania
}

Suzanne Maman

Jessie K. Mbwambo

Margaret Hogan

Gad P. Kilonzo

Michael D. Sweat

See next page for additional authors

Follow this and additional works at: https://knowledgecommons.popcouncil.org/departments_sbsr-hiv

Part of the Demography, Population, and Ecology Commons, Domestic and Intimate Partner Violence Commons, Health Policy Commons, Immune System Diseases Commons, International Public Health Commons, Medicine and Health Commons, Public Health Education and Promotion Commons, Virus Diseases Commons, and the Women's Health Commons How does access to this work benefit you? Let us know!

\section{Recommended Citation}

Maman, Suzanne, Jessie K. Mbwambo, Margaret Hogan, Gad P. Kilonzo, Michael D. Sweat, and Ellen Weiss. 2001. "HIV and partner violence: Implications for HIV voluntary counseling and testing programs in Dar es Salaam, Tanzania," Horizons Final Report. Washington, DC: Population Council. 
Authors

Suzanne Maman, Jessie K. Mbwambo, Margaret Hogan, Gad P. Kilonzo, Michael D. Sweat, and Ellen Weiss 


\title{
HIV and Partner Violence
}

\author{
Implications for HIV Voluntary \\ Counseling and Testing Programs \\ in Dar es Salaam, Tanzania
}

\section{(P) Population Council}

\section{Horizons is implemented by the}

Population Council in collaboration with

International Center for Researh on

Women (ICPN)

- International HIV/AIDS Alliance

Program for Appropriate 巨chnology in Health (PATH)

- The University of Alabama at Birmingham - Tulane University
Suzanne Maman Jessie Mbwambo Margaret Hogan Gad Kilonzo Michael Sweat Ellen Weiss 


\section{HIV and Partner Violence: Implications for HIV Voluntary Counseling and Testing Programs in Dar es Salaam, Tanzania}

\section{Suzanne Maman, ${ }^{1}$ Jessie Mbwambo, ${ }^{2}$ Margaret Hogan, ${ }^{2}$ Gad Kilonzo, ${ }^{2}$ Michael Sweat, ${ }^{1}$ Ellen Weiss ${ }^{3}$}

1 Johns Hopkins University, School Of Public Health, Baltimore, MD, USA

2 Muhimbili University College Of Health Sciences, Dar es Salaam, Tanzania

${ }^{3}$ Horizons Project/International Center for Research on Women, Washington, DC, USA 


\section{Acknowledgments}

The Tuelewane Project would not have been possible without the hard work of the research staff: Abassy Mlemba, Anna Kavugha, Caroline Chikokoto, Cliff Mbwambo, Elizabeth Chezi, Fred Mungure, Irene Mwanga, Methodia Muzale, Lusajo Kajula, and Peter Deogratius. Also critical to the research project was the support provided to the Muhimbili Health Information Centre (MHIC) by the Horizons Project and by USAID/Tanzania through Family Health International's Country Office and DATEX. The collaboration between Johns Hopkins University and the Muhimbili University College of Health Sciences (MUCHS) was made possible by a Fogarty research training grant and USIS Fulbright Fellowship to Dr. Suzanne Maman, which allowed her to remain in Dar es Salaam, Tanzania, during the data collection phase of the research project.

The research team and the MHIC staff worked diligently to make the research process a success as they sought to maintain high standards for the voluntary HIV counseling and testing service.

We are greatly indebted to the men, women, and couples who shared their experiences with us. We would like to thank Mary Ellsberg of the Women's Health Exchange and Sam Kalibala and Naomi Rutenberg of the Horizons Project/Population Council for reviewing an earlier draft of this report and providing valuable comments. Finally we would like to acknowledge the technical support from Ellen Weiss, Horizons Project/International Center for Research on Women, who worked with us on the research since the inception of the study. Thanks, Ellen.

USAID This study was supported by the Horizons Project. Horizons is funded by the U.S. Agency for International Development, under the terms of HRN-A-00-97-00012-00. The

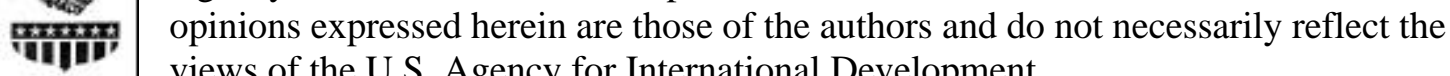
views of the U.S. Agency for International Development.

Published in February 2001.

\section{Population Council}

The Population Council is an international, nonprofit, nongovernmental humane, equitable, and sustainable balance between people and resources. The Council conducts biomedical, social science, and public health research and helps build research capacities in developing countries. Established in 1952, the Council is governed by an international board of trustees. Its New York headquarters supports a global network of regional and country offices.

Copyright (C) 2001 The Population Council Inc. 


\section{Table of Contents}

Executive Summary

Introduction 4

Linkages Between HIV/AIDS and Violence $\quad 4$

HIV Voluntary Counseling and Testing 4

Study Aims $\quad 5$

Methods 6

$\begin{array}{lc}\text { Study Design } & 6\end{array}$

$\begin{array}{ll}\text { Study Site and Population } & 7\end{array}$

Study Procedures $\quad 7$

Data Analysis $\quad 9$

Findings $\quad 12$

$\begin{array}{ll}\text { Deciding to Get Tested for HIV } & 14\end{array}$

$\begin{array}{ll}\text { Disclosing HIV Serostatus } & 16\end{array}$

HIV and Violence Against Women 22

Conclusion and Recommendations 29

References 


\section{Executive Summary}

An important component of HIV voluntary counseling and testing (VCT) programs is encouraging clients to inform partners of their serostatus. Yet many clients do not disclose results to partners. Studies have found that a serious barrier to disclosure for women is fear of a violent reaction by male partners and that HIV-infected women are at increased risk for partner violence (Gielen et al. 1997; Rothenberg et al. 1995; Temmerman et al. 1995). Building on previous research, this study explored the links between HIV infection, serostatus disclosure, and partner violence among women attending the Muhimbili Health Information Center (MHIC), a VCT clinic in Dar es Salaam, Tanzania.

The study first collected qualitative data from women, men, and couples $(n=67)$ who were MHIC clients. In the second phase, researchers enrolled 340 women after pretest counseling and prior to collection of test results; 245 of these women were followed and interviewed three months after enrollment and testing. ${ }^{1}$ Nearly a third of the sample were HIV-positive, almost half were married, and 50 percent were between the ages of 18 and 29 years and had less than seven years of education. The study followed WHO ethical and safety protocols for conducting research on violence against women.

\section{Key Findings}

Many women lack autonomy to make decisions about HIV testing. Male and female informants frequently referred to the need for women to "seek permission" from partners prior to testing. Men, on the contrary, generally made the decision to test on their own without soliciting prior consent. Most women in the study thought about testing for at least a month prior to actually seeking services.

Disclosure to partners by HIV-positive women has increased over time but is still significantly less than that for HIV-negative women. During a VCT study conducted at MHIC in the mid-1990s, only 27 percent of HIV-positive women who were tested as individuals disclosed their test results to a partner within six months after being tested (Grinstead, personal communication, 2000). In this study 64 percent of HIV-positive women who enrolled as individuals shared test results with a partner within three months of testing.

While the figure for disclosure among HIV-positive women is high, it is significantly lower than the 83 percent of HIV-negative women in the study sample who disclosed their test results to a partner. Overall the major reason for non-disclosure (52 percent) among all women, regardless of HIV serostatus, is fear of the partner's reaction, principally fear of abuse or abandonment.

Partner violence is a serious problem among many female VCT clients. More than a fourth of women interviewed agreed with the statement, "Violence is a major problem in my life."

\footnotetext{
${ }^{1}$ There were no significant differences between those followed and those lost to follow-up with regard to HIV status, age, marital status, education, and violence with a current partner in the last year.
} 
Male and female informants described violence as a way to "correct" or "educate" women, and said that violence that does not leave a physical mark on a woman is justifiable.

When asked about lifetime violence by an intimate partner, 38.5 percent of women had had at least one partner who had been physically abusive and 16.7 percent had had at least one partner who had been sexually abusive. ${ }^{2}$ Physical violence by a current partner was also commonly reported. Nearly a third of women had experienced at least one physically violent episode perpetrated by a current partner, such as slapping, twisting an arm, grabbing, punching, and kicking, in the three-month period prior to testing.

\section{A small proportion of women who disclosed their serostatus to partners reported a} negative reaction. Most women said that partners showed support and understanding when told the test results. However, the proportion of women who reported this positive reaction is significantly greater among HIV-negative women compared to HIV-positive women (66 percent vs. 37 percent, $p=.000$ ). Regardless of the women's serostatus, only a small percentage of women's male partners said they would come for HIV testing.

Twelve women ( 5 percent) reported one or more negative responses by a partner after disclosing their test results. This included being blamed for the results or for getting tested (two HIV-negative women and 8 HIV-positive women), physically assaulted (one HIV-negative woman and two HIVpositive women), and/or told to leave the house or abandoned (two HIV-positive women and one HIV-negative woman). Given the prevalence of violence among women in this study, there is considerable and justifiable fear of a partner's violent reaction, but little evidence that serostatus disclosure frequently leads to physical abuse and abandonment.

Women's HIV status is strongly associated with partner violence. Without adjusting for other variables, HIV-positive women were 2.68 times more likely than HIV-negative women to have experienced a violent episode by a current partner. Examining the interaction between women's age and HIV status and controlling for other sociodemographic variables, young HIVpositive women (18-29 years) were ten times more likely to report partner violence than young HIV-negative women. The strong association between prior history of violence and HIV infection does support the theory that violence plays a role in women's risk for HIV infection in this population.

\section{Program and Policy Recommendations}

\section{Encourage couple communication about HIV/AIDS and HIV testing when promoting}

VCT. This may make it easier for couples to get tested together and for individual women and men to share test results with sexual partners.

\section{Train HIV counselors to ask questions about partner violence and to encourage} disclosure when appropriate. At the time of this study counselors did not ask clients about experiences with partner violence. Counselors have an important role to play in helping clients

\footnotetext{
${ }^{2}$ Women were asked about number of partners who have hit, slapped, kicked, pushed, shoved, or otherwise physically hurt them, and physically forced them into sexual activity against their will.
} 
develop safe disclosure plans, which include finding out about the role violence plays in their lives. Therefore counselors need to be trained in how to ask sensitive questions about violence and to use this information to foster but not force disclosure among clients. Counselors must also be made aware of existing services to help women living in violent relationships so that they can make appropriate referrals when necessary.

\section{Ensure that clients are the ones to make decisions about partner notification of test}

results. Given the high prevalence of physical violence reported among these female VCT clients, involuntary disclosure of women's test results through a provider-referral system of notification may have negative consequences for women. A provider-referral system may also have a negative backlash on the number of clients who seek VCT services. A better alternative is to have counselors discuss disclosure plans with clients but to let the client decide whether to share results with a partner.

Institute community-based efforts to address sexuality and violence. Women are often at risk for both HIV infection and violence because of the behavior of their sexual partners. Developing an ethic of respect among men and women for the health and wellbeing of their intimate partners needs to be the foundation of both violence prevention and HIV prevention efforts. Implementing programs that focus on changing negative norms about male and female sexuality and on conflict resolution is crucial.

Conduct further research on HIV and violence. The findings from this study highlight the need to:

- Assess client-initiated approaches to facilitating serostatus disclosure, such as the use of a third party (e.g., a counselor, friend, religious person) chosen by the client to mediate disclosure to a partner.

- Identify the pathways through which partner violence increases women's risk of HIV infection.

- Examine the relationship between VCT clients' serostatus, their rate of serostatus disclosure to partners, and the incidence of negative outcomes of serostatus disclosure among women and men at other sites.

- Evaluate community-based HIV-prevention interventions that address partner violence to change harmful attitudes and norms about sexuality and violence. 


\section{Introduction}

\section{Linkages Between HIV/AIDS and Violence}

HIV/AIDS and violence are two of the major health problems affecting the lives of millions of women worldwide. Violence is a neglected public health problem that has only recently gained the attention of researchers, policymakers, and practitioners. Between 20 to 50 percent of women report experiencing violence by an intimate male partner (Heise, Ellsberg, and Gottmoeller 1999).

Investigators have hypothesized several ways in which the epidemics of HIV and violence overlap in the context of women's lives. First, coercive sexual intercourse may directly increase women's risk for HIV through physiological trauma (Choi et al.1998; He et al. 1998; Van der Straten et al. 1995; Zierler et al. 1996). Second, violence and threats of violence may limit women's ability to negotiate safe sexual behaviors (Gupta and Weiss 1993; Karim et al. 1995; Van der Straten et al. 1998; Wingood and Diclemente 1997; Worth 1989). Third, women who have been sexually abused in childhood may participate in more sexual risk-taking behavior as adolescents or adults, thereby increasing their risk for HIV infection (Jinich et al. 1998; Handwerker 1993; Zierler et al. 1991).

Finally, another association between HIV and violence occurs among women who receive HIV counseling and testing. The literature from the United States and sub-Saharan Africa suggests that women who disclose their serostatus to partners may be at increased risk for violence and that the threat of violence may play a key role in deterring women who wish to disclose their serostatus to partners (Gielen et al. 1997; Rothenberg et al. 1995; Temmerman et al. 1995).

\section{HIV Voluntary Counseling and Testing}

There has been growing support and demand for HIV voluntary counseling and testing services (VCT) that foster risk-reduction behavior based on knowledge of serostatus and link HIV-infected individuals with care and support services. There are several compelling arguments for HIV VCT: (1) individuals have a right to know their infection status to protect themselves and others from infection, (2) HIV VCT may enable people to cope with the anxiety associated with the uncertainty of not knowing one's serostatus, (3) early detection of HIV may improve the medical and psychological support for HIV-infected persons, and (4) HIV VCT has been shown to promote behavior change (de Zoysa et al. 1995). Recently, the impact of HIV VCT was rigorously evaluated through a randomized control trial to test its efficacy in reducing risk behaviors among women and men in Dar es Salaam, Nairobi, and Port of Spain. The study found that individuals randomized to receive HIV VCT significantly change their risk behaviors compared to those who receive health education (The Voluntary HIV-1 Counseling and Testing Efficacy Study Group 2000).

Despite the benefits of HIV VCT, low rates of disclosure of HIV serostatus have limited the effectiveness of HIV voluntary counseling and testing programs. For example, only 27 percent of HIV-positive women from Dar es Salaam who participated in the previously mentioned efficacy trial disclosed their results to their partners, according to $\mathrm{O}$. Grinstead in a personal communication in June 2000. Serostatus disclosure to partners is an important public health goal for a number of 
reasons. First, individuals who are at risk for HIV infection have a right to be informed of their risk. Disclosure may encourage more individuals who are at risk to seek testing for HIV. An increase in the number of individuals who are tested may lead to a reduction in sexual risk-taking behavior, which may ultimately lead to a decrease in the transmission of HIV. Research has shown that disclosure between couples may facilitate sustained behavior change (Kamenga et al. 1991). Disclosure may also reduce the psychological discomfort that is associated with knowing that one is HIV-positive. Finally, disclosure may facilitate the adoption of other important health behaviors that may improve the management of HIV infection.

A number of studies have reported negative outcomes of HIV VCT for some groups. These outcomes include psychological distress in couple and family relationships (Kamenga et al. 1991; Pelzer 1989), violence against women who disclose results to partners (Gielen et al. 1997;

Rothenberg et al. 1995; Temmerman et al. 1995), and discrimination against and stigmatization of individuals who have been identified as HIV infected (Annas 1993; Earickson 1990; Santana 1991). Rothenberg et al. (1995) found that among a sample of 136 health care providers serving HIV-infected women in Baltimore, 24 percent of providers had at least one female patient who experienced physical abuse following disclosure to a partner. Similarly, Gielen et al. (1997) report that one quarter of the 50 women that they interviewed experienced negative consequences after disclosure to partners, including rejection, abandonment, verbal abuse, and physical assault. In Nairobi, Kenya, Temmerman et al. (1995) report that among the 66 women in their study who disclosed results to partners, eleven were chased out of their homes or replaced by another wife, seven were beaten, and one committed suicide. Building on previous research, this study explored the links between HIV infection, serostatus disclosure, and partner violence among women attending a VCT clinic in Dar es Salaam, Tanzania.

\section{Study Aims}

The overall goals of the study were to: (1) investigate the attitudes, beliefs, and experiences relating to HIV testing, serostatus disclosure, and partner violence of women seeking VCT, and (2) disseminate this information in order to inform policy and program development. The study was conducted in two phases. Qualitative data were gathered in Phase 1 to:

- Describe the decision-making process for HIV testing and serostatus disclosure among women, men, and couples seeking VCT.

- Define violence in the Tanzanian cultural context.

- Develop instruments for the second phase of data collection.

The aims of Phase 2 were to:

- Measure the prevalence and identify the correlates of violence among female VCT clients.

- Determine the rate and describe the outcomes of HIV serostatus disclosure to partners by female clients.

- Describe the associations between HIV and violence among women in this population. 


\section{Methods}

\section{Study Design}

\section{Phase 1 (qualitative)}

During this phase we conducted in-depth interviews with 15 women, 17 men, and 15 couples who were 18 years or older and had been through the HIV counseling and testing process at least one month prior to the interview. Men, women, and couples were recruited by the HIV counselors at the Muhimbili Health Information Center (MHIC) clinic. Counselors briefly described the study objectives and study procedures to eligible clients and asked if they were interested in participating.

Individual clients who expressed an interest in participating in the study were referred to one of the two study ethnographers, who described the study in more detail and obtained informed consent.

Male and female partners within couples were informed about the study together and were provided with an opportunity to discuss participation in private; interested couples were then separated for the actual interviews. A male ethnographer interviewed the male partner, and a female ethnographer interviewed the female partner. Both male and female partners gave informed consent for participation individually before the interviews began.

A semi-structured field guide outlined the major topics for the in-depth interviews and suggested probes for interviewers. In-depth interviews were audiotaped, transcribed, translated, and then entered into a word processing file for analysis. Each interview took place in a private room within the MHIC and lasted approximately 1 to 1.5 hours.

\section{Phase 2 (quantitative and qualitative)}

In Phase 2, 340 women enrolled immediately after receiving pretest counseling and before the collection of test results. Of these, 245 women were followed and interviewed three months after enrollment and testing. The follow-up structured survey interview took place in a private room within the MHIC and lasted approximately 1.5 hours. The interview topics included personal demographic information (age, education, marital status, parity); household socioeconomic status; financial autonomy; partner characteristics; HIV testing and disclosure experiences; history of violence (childhood, lifetime adult, current partner); associated physical, social, and health consequences of violence; and attitudes and norms regarding gender roles.

We included filter questions within the survey to help identify women who would be eligible for an additional in-depth interview. These included women who reported negative outcomes of HIV serostatus disclosure, women who said that the reason they did not reveal their serostatus to a partner was fear of the partner's reaction, and women who reported physical violence with a partner in the three-month period of time since being tested for HIV. Any woman who met one of these criteria was asked whether she would be willing to stay for an additional 30 minutes to answer more detailed questions about her disclosure experiences. We recruited every woman who was eligible and who agreed to be interviewed until 20 follow-up in-depth interviews were conducted. 


\section{Study Site and Population}

The study was carried out among men, women, and couples attending MHIC from January to December 1999. MHIC is a free-standing, voluntary HIV counseling and testing clinic on the grounds of Muhimbili Medical Centre (MMC), the national referral hospital and also the largest public hospital in the country; MMC is adjacent to the Muhimbili University Department of Psychiatry.

MHIC opened in 1995 as part of a large multi-country research study on the efficacy of voluntary counseling and testing on reducing risk behavior among individuals and couples. In 1997, when the Counseling and Testing Efficacy Study was completed, the site changed its focus from primarily conducting research to the exclusive providing services. The United States Agency for International Development (USAID), through Family Health International's Country Office (FHICO) and DATEX VSHP, has provided the funding for service provision since 1997. The clinic has four full-time counselors who have worked with the clinic since its inception in 1995. In addition to the counselors there is one laboratory technician, one screener, one receptionist, one data entry clerk cum secretary, and one administrative assistant.

Men, women, and couples recruited for the study received standard WHO and CDC procedures for counseling and testing, including a pretest counseling session by trained counselors, HIV testing on site, and a posttest counseling session approximately two weeks after testing. Clients were invited to return to the clinic if they had any questions, but there was no formal protocol for further counseling.

The number of clients who use services at the MHIC has grown considerably in the last five years. When the clinic opened in 1995 an average of 80 new clients were seen per month. During 1999 the number of new clients grew to an average of 394 per month. There has also been an increase in the number of couples at the MHIC. The average number of couples who came to the MHIC in 1998 was 10.5 per month. This average increased to 23 couples per month in 1999 and 25 per month in January-May 2000. Twenty-three percent of MHIC clients are HIV-positive (33.4 percent women and 15 percent men) and the rate of discordance among couples at the MHIC is 11 percent. $^{3}$

\section{Study Procedures}

\section{Screening and enrollment}

When women registered at the clinic, the screener identified clients who were 18 years of age or older, had a primary partner, and would be in Dar es Salaam for at least the next three months, and briefly informed them about the study. The screener asked the eligible women if they would be interested in speaking to a study enroller about participating after they had completed their pretest counseling and had their blood drawn. Approximately 90 percent of clients who were informed about the study agreed. The major reason given by those who refused was lack of time.

An enroller explained the study in more depth to each woman, answered questions, conducted informed consent with women who agreed to participate, and then conducted a 30-minute

\footnotetext{
${ }^{3}$ Source: The MHIC service utilization database.
} 
enrollment interview. The enrollment interview was primarily designed to collect demographic and personal contact information that would assist in tracing women in three months to remind them of their appointments. Providing contact information was entirely optional. Over three quarters of women provided at least one form of contact information. At the completion of the enrollment interview, the enroller gave each woman an appointment to return three months from the date of enrollment; the return date was marked by the enroller on the woman's clinic appointment card.

\section{Tracing}

The enrollers asked each participant to provide a post office box, a phone number, a home address, a work address and/or one other address at which she could be reached. They also asked participants to provide the name of another person who could be contacted in case the tracers failed to contact the participant. Participants were told that any information sent through the mail would be sent in a plain envelope with no clinic identification information. Enrollers also asked participants how they would like the tracers to identify themselves if they telephoned or visited one of the physical locations provided by the women. Most women wanted the tracers to identify themselves as being from Muhimbili.

Letters were posted two weeks before the scheduled appointments. One week before appointments, women who provided telephone contacts received calls. Women who missed their appointment received visits from the tracers a week later. Tracers attempted at least three visits to women before declaring them lost to follow-up. No negative incidents resulted from tracing activities. The fact that one quarter of women chose not to leave any tracing information is an indication that women understood the voluntary nature of the study.

\section{Translation}

Ethnographers audiotaped and transcribed all in-depth interviews into a hand-written verbatim Kiswahili transcript. Ethnographers used a transcription machine or hand-held microcassette recorders to transcribe all in-depth interviews.

The project translator then translated each Kiswahili transcript into a hand-written English transcript. When there were questions or problems with translation, the translator consulted one of two Tanzanian co-investigators. During weekly project meetings there was often lengthy debate about how to translate certain Kiswahili phrases. When specific words or phrases could not be translated into English, the Kiswahili word or phrase was maintained accompanied by rough English translations. The translator assisted with the translation of all data collection instruments and also translated all open-ended questions in the survey interview.

\section{Data entry and management}

Data management systems were developed for both qualitative and quantitative data. Two data entry clerks entered all qualitative and survey data for both phases of data collection. Data entry clerks developed the data entry frame in SPSS. Each clerk manually checked the work of the other; both data entry clerks cleaned data. 
The importance of confidentiality was emphasized throughout the data management system. Only one tracking book linked the study identification numbers with the HIV status of participants. No project staff members could take the tracking book containing identifying information on participants outside the clinic and senior project staff members were made responsible for these books. No breaches in confidentiality were reported.

\section{Data Analysis}

\section{Measurement of violence}

A major limitation of earlier studies on violence is their ambiguous and inconsistent measurement of physical, sexual, and psychological violence (Maman et al. 2000). Variations in definitions, study methods, time frames of assessment, and sampling frames all contribute to the difficulty in understanding the scope and severity of violence against women. In an attempt to generate consistent measures of violence, in this study we explored violence from a qualitative as well as a quantitative perspective.

In Phase 1 of data collection, we asked informants to define violence in Kiswahili, to identify situations in which violence may be justified, to describe how violence is used by people in the community, and to relate their personal experiences with violence in intimate partnerships. The elicitation of local terms for violence and the description of norms surrounding violence were useful in the second phase of data collection, in which we measured the scope and severity of violence across a woman's lifetime and specifically since the time of testing.

In the second phase of data collection we asked women about their personal experiences with violence since childhood. To describe the prevalence of childhood sexual abuse we asked women to tell us how many times before the age of 12 someone older had forced them to have sex or forced them to do something sexual to them. To describe lifetime adult violence we asked informants to tell us how many of their partners had hit, slapped, kicked, pushed, shoved, or otherwise physically hurt them. We also asked women to tell us how many of their partners had yelled at them or called them names at least once a week and how many of their partners had physically forced them into sexual activity against their will. To measure violence with their current partner we adapted the Conflict-Tactic Scale (CTS) for use in the Tanzanian context (Straus et al. 1996).

The CTS was administered to women both at the time of enrollment and again at the three-month follow-up interview. The CTS is used to measure different strategies that couples use to resolve conflicts, including physical violence. The scale has been used extensively in the United States to measure violence in intimate partnerships but has not been widely applied in international settings. During the first phase of data collection we pretested the scale with women attending the VCT clinic and the respondents had few problems understanding the scale items. However, informants did have trouble with the response categories that are designed to measure the frequency of each variable. Thus, we modified the response categories from the original scale that are never, once, twice, 3-5 times, 6-10 times, 11-20 times, and more than 20 times to the following: never, once, 2-3 times, 4-10 times, and more than 10 times. We asked about the frequency of items during two different referent periods, in the last three months (time since HIV testing) and before the last three 
months. The CTS subscales of physical violence and verbal abuse demonstrated good internal consistency; reliability coefficients for these scales were 0.9496 and 0.8013 .

\section{Qualitative analysis methods}

We analyzed data using two different qualitative analysis techniques. First, we reviewed data for main themes and then coded for retrieval and analysis (Bernard 1995). Second, we created matrices based on the data to facilitate the comparison of text across different categories of informants (Miles and Huberman 1994). For example, we created a matrix to compare the testing and disclosure narratives of men and women.

\section{Quantitative analysis methods}

We analyzed quantitative data using SPSS for Windows, version 7.5. HIV serostatus was cross-tabulated with demographic and descriptive variables using chi-square statistics to examine for potential confounders to the primary associations of interest, namely experiences of violence during a woman's lifetime and HIV serostatus. We examined and tested the association of HIV serostatus with experiences of violence using unadjusted and adjusted logistic regression models for binary outcomes and linear regression models for interval outcomes, while simultaneously controlling for the study confounders.

To examine in more detail the associations and possible predictors of physical violence with the current partner, we initially grouped variables into categories representing characteristics of each woman (age, education, religion, socioeconomic status, marital status, consumption of alcohol, perceived social support, financial autonomy, attitude towards gender roles, attitude toward physical punishment, and degree of urbanization), individual characteristics of the partner (age, education, employment status, religion, consumption of alcohol, and other intimate relationships), characteristics of the relationship (duration, decision-making patterns, and age gap between partners), and characteristics of the living environment (shared housing). We used backward stepwise logistic regression techniques that incorporated variables from each category to simultaneously adjust for potential confounders and to formally test interactions.

We compared the characteristics of HIV status, age, marital status, education, and experiences with violence of the women who were followed with those women who were lost to follow-up (see Table 1). The only difference that approached significance was the baseline report of violence with a current partner prior to the last year. Among women who were followed, 47.6 percent reported violence with their current partner prior to the last one year, compared to 61.8 percent of women who were lost to follow-up ( $p=0.068)$, which indicates that our final estimate of violence within the population of women who were followed may be an underestimation of the actual level of violence experienced by women who seek VCT services. 
Table 1 Comparison of women followed and lost to follow-up

\begin{tabular}{|c|c|c|c|}
\hline Characteristic & $\begin{array}{l}\text { Followed } \\
\text { n= } 245 \\
\%\end{array}$ & $\begin{array}{l}\text { Lost to } \\
\text { follow-up } \\
n=95 \\
\%\end{array}$ & $p$ value \\
\hline \multicolumn{4}{|l|}{ HIV status } \\
\hline HIV-positive & 29.8 & 26.8 & .582 \\
\hline HIV-negative & 70.2 & 73.2 & \\
\hline \multicolumn{4}{|l|}{ Education } \\
\hline Primary (0-7) & 51.5 & 53.6 & .463 \\
\hline Secondary (8-13) & 38.0 & 26.8 & \\
\hline Post-secondary (14-22) & 10.6 & 19.6 & \\
\hline \multicolumn{4}{|l|}{ Violence with current partner* } \\
\hline In last one year & 31.9 & 39.2 & .233 \\
\hline Prior to last year & 47.6 & 61.8 & .068 \\
\hline \multicolumn{4}{|l|}{ Marital status } \\
\hline Married & 45.3 & 49.5 & .263 \\
\hline Not married/living together & 11.8 & 6.2 & \\
\hline Not married/not living together & 35.1 & 49.5 & \\
\hline Separated/divorced/widow & 7.7 & 3.1 & \\
\hline
\end{tabular}




\section{Findings}

We present our findings according to three topic areas: (1) deciding to get tested for HIV, (2) disclosing HIV serostatus, and (3) HIV and violence against women. For each topic, key qualitative findings (primarily from Phase 1) are presented with the quantitative results from Phase 2. As part of our analysis we examined the influence of individual, relational, and environmental factors for each of the topics. Individual factors refer to demographic and cognitive variables, while relational factors refer to characteristics of the partner and the dynamics between partners. Environmental factors explored include the physical environment, access to resources, social support, and living arrangements.

As mentioned previously, 62 informants participated in in-depth interviews in Phase 1 . These included 15 women (2 HIV-negative, 13 HIV-positive), 17 men (11 HIV-negative, 6 HIVpositive), and 15 couples. Among the couples there were 12 concordant HIV-negative couples, 1 concordant HIV-positive couple, and 2 discordant couples (1 HIV-positive man and HIV-negative woman; 1 HIV-negative man and HIV-positive woman).

In Phase 2, 245 women were interviewed three months after receiving their HIV test results. The median age of these women was 30 years, the median number of years of education was seven, almost half were married (46.4 percent) and a significant proportion were in relationships but were neither married nor living with their partners (36.4 percent). The average monthly salary was 40,000 Tanzanian shillings (equivalent to US\$50) and the median duration of relationships was four years. Nearly 30 percent of these women were HIV-positive. The prevalence of HIV infection we found among women who attended the MHIC and participated in this study (29.8 percent) is higher than the HIV prevalence estimated by the Tanzania National AIDS Control Program for women in urban areas (18.3 percent). Therefore our results cannot be generalized to a wider population of women. Table 2 summarizes the sociodemographic characteristics of the Phase 2 sample. 
Table 2 Sociodemographic characteristics of the sample $(n=245)$

\begin{tabular}{|c|c|c|c|c|}
\hline Characteristic & $\begin{array}{l}\text { HIV- } \\
n=172 \\
\%\end{array}$ & $\begin{array}{l}\text { HIV+ } \\
n=73 \\
\%\end{array}$ & $\begin{array}{l}\text { Overall } \\
\mathrm{n}=245 \\
\%\end{array}$ & $p$ value \\
\hline \multicolumn{5}{|l|}{ Age } \\
\hline $18-29$ & 54.7 & 35.6 & 49.0 & .000 \\
\hline $30-39$ & 25.6 & 52.1 & 33.5 & \\
\hline $40-55$ & 19.8 & 12.3 & 17.6 & \\
\hline \multicolumn{5}{|l|}{ Education (years) } \\
\hline $0-7$ & 45.9 & 65.8 & 51.8 & .004 \\
\hline $8-13$ & 40.1 & 31.5 & 37.6 & \\
\hline $14-22$ & 14.0 & 2.7 & 10.6 & \\
\hline \multicolumn{5}{|l|}{ Religion } \\
\hline Catholic & 32.6 & 31.5 & 32.2 & .108 \\
\hline Protestant & 39.5 & 26.0 & 35.5 & \\
\hline Muslim & 26.7 & 41.1 & 31.0 & \\
\hline Other & 1.2 & 1.4 & 1.2 & \\
\hline \multicolumn{5}{|l|}{ Marital status } \\
\hline Monogamous marriage & 43.2 & 38.6 & 41.8 & .019 \\
\hline Polygamous marriage & 4.1 & 5.7 & 4.6 & \\
\hline $\begin{array}{l}\text { Not married/living } \\
\text { together }\end{array}$ & 11.2 & 12.9 & 11.7 & \\
\hline $\begin{array}{l}\text { Not married/not living } \\
\text { together }\end{array}$ & 39.1 & 30.0 & 36.4 & \\
\hline $\begin{array}{l}\text { Separated/widowed/ } \\
\text { divorced }\end{array}$ & 2.4 & 12.9 & 5.4 & \\
\hline \multicolumn{5}{|l|}{ Employment status } \\
\hline Employed & 72.1 & 60.3 & 68.6 & .068 \\
\hline Not employed & 27.9 & 39.7 & 31.4 & \\
\hline \multicolumn{5}{|l|}{ Socioeconomic status } \\
\hline Low & 26.7 & 46.6 & 32.7 & .005 \\
\hline Medium & 42.2 & 38.4 & 42.4 & \\
\hline High & 29.1 & 15.1 & 24.9 & \\
\hline \multicolumn{5}{|c|}{ Duration of relationship (years) } \\
\hline $0-2$ & 35.8 & 23.8 & 32.5 & .047 \\
\hline $2-4$ & 17.6 & 22.2 & 18.9 & \\
\hline $4-11$ & 21.2 & 36.5 & 25.4 & \\
\hline Over 11 & 25.5 & 17.5 & 23.2 & \\
\hline \multicolumn{5}{|l|}{ Prior HIV-1 testing experience } \\
\hline First-time tester & 72.7 & 77.8 & 74.2 & .428 \\
\hline Tested before & 27.3 & 22.2 & 25.8 & \\
\hline \multicolumn{5}{|l|}{ Couple/individual testing } \\
\hline Tested as an individual & 85.0 & 92.0 & 86.9 & .149 \\
\hline Tested as a couple & 15.0 & 8.0 & 13.1 & \\
\hline
\end{tabular}




\section{Deciding to Get Tested for HIV}

\section{Individual factors}

Perceived benefits of HIV testing: Although both the men and women interviewed in Phase 1 described HIV testing as a means of planning for the future, the major factors that motivated them to seek testing differed markedly.

- Male informants who came to the clinic alone primarily described HIV testing as a preventive health measure. Some men used HIV testing as a way to confirm their suspected HIV-negative serostatus and the negative serostatus of a partner before committing to a relationship. Men also described HIV testing as a way to regain a partner's trust after being suspected of infidelity. According to a 43-year-old, HIV-negative male:

Early last year I got this disease called herpes zoster. When I got this disease my partner panicked...she was feeling that I was already infected with HIV. Well, she didn't believe me at all. I had to use another way of telling her that. Well, I will go to test.

- Women's decision to test for HIV was primarily motivated by the sickness or death of either a child or a partner. Women did not describe HIV testing as a preventive health measure; rather, they described it as a means to confirm their HIV-positive status or to check for other reproductive health problems, particularly fertility problems. A 31-year-old, HIV-positive female noted, "I came to test because the husband was sick... and I had already lost a small child. I told him, 'Because of the way the situation is I want to go and check."'

- For couples, the decision to test for HIV was usually initiated by a single partner, who in most cases was the male. Couples described testing as a preventive health measure that they used before unprotected sexual intercourse, marriage, or pregnancy. Several couples also mentioned testing as a means to reaffirm one's commitment to the relationship and as a way to try to diagnose and treat other reproductive health problems. Two couples interviewed said that the church required them to be tested before marriage.

Perceptions of risk: Perception of personal susceptibility to HIV infection seems to be the primary factor motivating women to overcome other barriers to HIV testing. The women we interviewed in Phase 1 described several reasons why they felt that they might be infected, such as their own illness or the illness or death of a child and/or partner. Only a few men were motivated to undergo testing because they feared they were already infected as a result of sickness or past sexual behaviors. Given the percentage of female clients who are HIV-infected (33.4 percent vs. 15 percent, based on MHIC service data) it is not surprising that the women expressed a greater sense of personal susceptibility to HIV infection than did the men.

\section{Relational factors}

Partner's attitudes toward HIV testing: The social meaning of HIV testing and what partners ascribe to these meanings are important barriers in the decision to undergo testing and whether to involve a partner in the testing experience. For both men and women, HIV testing implied a lack of 
faith in the partnership, a lack of trust in a partner's behavior, and an acknowledgment of their own risky sexual behaviors.

When discussing HIV testing with a partner, participants were afraid that communicating their desire to be tested could threaten the relationship. Several women presented HIV testing as another strategy the couple could use to try to understand the reproductive health problems they were having. According to a married, 29-year-old, HIV-positive woman, "It is nearly seven years, we aren't blessed with a child. Therefore I beg you to go try our luck. He said, 'Okay, let's go.' Therefore he agreed without any problems." Similarly, a few men also presented HIV testing to partners as one step in the search for cures to their lingering health problems. A 27-year-old unmarried HIV-negative male reported: "I just said I was sick and wanted to check my health. I was sick with typhoid...and not getting cured."

Decision-making autonomy: Male and female informants frequently referred to the need for women to "seek permission" from partners before HIV testing. A 38-year-old, married, HIVnegative female noted:

Now if you want him not to be angry, first you must educate him. You educate him nicely that there is a clinic that provides information about your health.... He can agree or he can tell you to go alone for testing and bring the results.

In contrast, men generally made the decision to test for HIV on their own without soliciting the consent of their partners. Informants reported that men could pass the clinic, see an advertisement, and drop in to be tested, whereas women would be less likely to drop into the clinic as they were passing by and get tested. According to a married, 36-year-old, HIV-negative male:

Let's take an example. She passes, she finds there is a centre of testing like here. She enters there and asks about it. She is told that here we are testing for AIDS. For instance, now she can't test for just good intention. When she goes home she can't say she went to that certain place. Now if it is a man having mind to test it is not a problem.

Fear of partner's reaction: The major perceived barrier to HIV testing for women informants was fear of a partner's reaction. Several women chose not to inform their partners about their intention to get tested for HIV because they feared the reaction. For many of the women who talked to their partners about testing before coming into the clinic, this discussion was often tense and hostile. The decision to get tested was often one that women fought hard to defend. According to a married, 31year-old, HIV-positive woman:

We exchanged words when I was thinking of coming for testing. I was telling him that I was coming to test and he kept refusing. I told him I must go now even if you refuse. He kept asking me, "For what reason are you going to test? Don't go. Why should you go to test?"

If a woman underwent a test without the consent of her partner, conflict frequently arose. In one case a woman's partner threatened to abandon her if she was tested and found to be HIV-positive. 
Oh we argued for nearly three or four months [about testing]. I told him I was going to test and he said, "What are you sick from?" So I went. I returned home and told him, "I have already gone and the card is there. After two weeks I am going to take the results." He yelled, "Didn't I tell you don't go there. I am not going to test. If it is to die then just let me die.... When you return if you are sick I am going to leave you."

Several of the men in the Phase 1 sample also feared their partners' reaction but for very different reasons. Men did not fear tension, hostility, or possible abandonment by a partner but were afraid that the partner might discover that they had had extramarital affairs.

\section{Environmental factors}

Time and money: In Tanzania, where the per capita gross domestic product is less than US\$750 (US Central Intelligence Agency Database, 2000), we expected that the direct and indirect costs associated with HIV testing would be barriers to HIV testing. We were somewhat surprised that informants did not mention environmental barriers such as time and cost more often. Only one male informant said that lack of time would prevent his partner from getting tested; another male informant cited cost as a barrier for his partner to be tested. It is possible that when asked directly, individuals are less likely to think about the factors that are beyond their immediate control that may influence health behaviors such as HIV testing.

\section{Disclosing HIV Serostatus}

\section{Individual factors}

HIV serostatus: Many informants from Phase 1 described the decision to tell a partner their HIV test results as a difficult process, one made even worse when their test results were positive. We asked each informant how a man would react if his female partner told him that she tested positive for HIV and how this reaction would differ if she told him that she tested negative. The informants said that a man would first react to the fact that his partner had undergone testing without his permission, and then his response would depend on whether the results were positive or negative. If the HIV test results were positive, most informants said that the disclosure would cause a great deal of strife in the household, perhaps leading to physical abuse and abandonment. Most informants said that a partner would react positively if the HIV test results were negative.

Gender: Despite the fact that proportionally fewer men than women in our sample of 62 informants shared their HIV test results with their partners, in general, men described fewer barriers to disclosure than did women. The men who chose not to disclose their HIV serostatus to partners agonized less over that decision. For most of the men who shared their results, the process of disclosing even HIV-positive results was not particularly troublesome. According to an HIVpositive, unmarried male, age 29 , disclosing his test results was not an eventful experience:

[How did she receive the results?] She stayed silent. She didn't say anything. [How long did it take to tell her?] Not long. It was like normal conversation. [Did you tell her the same day? I I told her the same day when I returned. 


\section{Relational factors}

Fear of partner's reaction: Some women described fear of a partner's reaction as a major barrier to disclosure of their HIV serostatus. Women feared abandonment most, as described by a young, HIV-positive woman involved in a relationship with an older, married man:

He didn't know I came to test. [Why didn't he know?] I don't live with him. He has his wife there at home. If I tell him that I have tested he will think of the time we had sex without a condom. He may decide not to come at all. I can't tell him.

Negative reactions, particularly abandonment, were a reality for some women who chose to disclose test results to their partners, as illustrated by the quote below from a 29-year-old, HIV-positive woman:

Now another time I was suffering from a problem of skin disease. I think that the $H I V$ was starting. It occurred around my breasts. Now when it happened he just became very quarrelsome and was beating me. In fact, I felt bad. I lost weight; his quarrelsome behavior just doesn't end. He can say anything even in front of people. I used to tell him, "Let's go for testing together." But he refused. The day I came for testing I didn't tell him. It took two weeks to tell him. He had decided we get separated but I think it is because of that disease. He wants us to leave each other and me to go away to die.

Some men also mentioned fear of a partner's reaction as a barrier to disclosure. However, the reactions that men feared were significantly different from those anticipated by women. Men did not fear physical assault or abandonment; instead, they feared that their partners would panic. Men also feared losing status in the eyes of their partners because their marital infidelities would be exposed.

Communication about HIV testing: The tension that was described about the decision to disclose HIV status to partners was strongly influenced by the extent to which the partner was aware of and involved in the HIV testing experience. Several informants mentioned the importance of communication prior to testing. Although the ideal would be to talk with a partner prior to testing, many women could not achieve this ideal. If a woman underwent testing on her own without informing her partner, she also risked being blamed as the source of infection.

For women who either did not inform their partners they were going to be tested or whose partners were not supportive of their decision to be tested, HIV serostatus disclosure sometimes led to verbal, and in one case physical abuse:

It took two weeks to tell him. He told me, "You know who has brought it?" I told him, if you are blaming me then blame me but you are the one who has brought it. (HIV-positive female, 31 years old)

When I informed him of the results there was endless violence in the house. (HIVpositive female, 29 years old) 


\section{Environmental factors}

Social support: Some informants mentioned support from friends, family, and other trusted community members, such as priests, as a factor that helped them disclose their HIV serostatus. In one case a woman who tested positive for HIV tried to encourage her husband to get tested. When he refused she called upon their priest, who counseled the husband to agree to the test. The priest also helped the woman through the entire process of sharing results with family members and coming to terms with the results.

Counseling environment: Some informants mentioned the counseling environment as important in helping them cope with the anxiety associated with learning one's serostatus and the fear associated with sharing that status with a partner. According to an unmarried, 22-year-old, HIV-negative male:

If you get those early explanations [pretest counseling] you have already prepared yourself. That day I got a very long explanation, like half an hour, before going to take my blood. As a result of those words from that mother [counselor] you can take those results easy.

\section{Disclosure Experiences Of Couples Who Test Together}

Couples who come to the MHIC to test for HIV first receive pretest counseling together. In the posttest counseling session counselors give each member of the couple his or her results individually, and then provide an opportunity for the couple to come together to discuss their results, which most couples accept.

For the ten couples who were HIV-negative seroconcordant, the counseling, testing, and disclosure were very positive. According to a 42-year-old, HIV-negative, married male:

After receiving the results together, for truth, even work that day I didn't do. I saw it as if that day is when I married my wife. Because between us every person started to trust each other. As if we have locked our marriage today! It brought confidence for us. Each of us said, "I was suspecting you" thus... everything was put open that day.

For the two couples who were serodiscordant for HIV, the counseling and testing experience was mixed. One such couple in our sample (male HIV-positive, female HIV-negative) said that the counseling and testing did not significantly improve or worsen the relationship. Of the second serodiscordant couple (male HIV-negative, female HIV-positive), interestingly, the man said that knowing their HIV status strengthened their relationship and increased the trust between them, whereas the woman felt that the experience had not significantly changed their relationship.

Both the male and female partner of the seroconcordant, HIV-positive couple said that their relationship has suffered since they learned their test results. They have remained together but both said they were most saddened by their decision not to have children. 


\section{Disclosing serostatus: findings from the quantitative data}

Among the 245 women we interviewed three months after HIV testing, 9.8 percent indicated that they did not share their HIV test results with anybody. When disaggregated by serostatus, 17 percent of HIV-positive women told nobody about their results, versus 7 percent of HIV-negative women. Seventy-nine percent of women said they disclosed their HIV test results to a partner, 31 percent had told a sister, 26 percent had told a female friend, 22 percent had told a mother, and 12 percent had told a brother. Sixty-five percent of women said that the first person they told was a primary partner. The pattern of disclosure tended to be first to tell a sexual partner and then to tell a female confidant, either a sister or a female friend.

A substantial proportion of women (44 percent) identified at least one person with whom they did not want to share their HIV test results. Thirty percent said that person was a relative, 27 percent said it was their parents, 12 percent said it was a partner, 7 percent said it was a neighbor, and 6 percent said it was a friend. The reasons that women did not want to share test results with these people were fear of loss of confidentiality ( 31 percent), fear of worrying other people ( 26 percent), and fear of negative outcomes ( 20 percent).

\section{VCT clients compared to participants in HIV perinatal transmission trials}

In this study 79 percent of women said that they shared their test results with a partner. When disaggregated by serostatus, a significantly greater proportion of HIV-negative women ( 83 percent) as compared to HIV-positive women (69 percent) shared test results with their partners three months after HIV testing $(p=.025)$.

A study investigating the efficacy of vitamin A supplementation on the transmission of HIV from mother to child reported much lower rates of serostatus disclosure to partners among HIV-positive women. The study, which is being conducted at MUCHS in collaboration with Harvard School of Public Health, found that only 22 percent of 1,000 HIV-positive women enrolled in the trial reported that they shared test results with a primary partner 2 months after HIV testing (Antelman et al. 1999). This increased to 37 percent 41 months after HIV testing. In the PETRA study, another HIV perinatal transmission trial in Dar es Salaam, only 16.6 percent of the 288 pregnant, HIVpositive women enrolled reported that they shared their test results with a partner 18 months after they had been tested (Killewo et al. 1999).

Several factors may account for the large disparity in disclosure rates reported among the women enrolled in our study compared to those enrolled in the perinatal transmission trials.

- Women who sought services at the VCT clinic specifically came to learn their HIV serostatus, whereas women enrolled in the perinatal trials were offered the opportunity to be tested for HIV and to enroll in the trial during the course of their normal antenatal clinic visit. These women were not psychologically prepared to be tested, to learn their test results, and to share their test results with their partners and others the way that women at the MHIC were. For the women at the MHIC, the decision to test was a difficult one and on average, most had thought about testing for at least one month before actually seeking services. Thus, it is clear that the different disclosure rates reflect that these are two very different populations of women. 
- Women at the MHIC receive supportive counseling related to disclosure that may not be available to the same extent to the women enrolled in the perinatal transmission trials.

\section{HIV serostatus disclosure over time at MHIC}

In the earlier HIV Counseling and Testing Efficacy Study conducted at the MHIC during the mid1990s, investigators found that 27 percent of HIV-positive women enrolled as individuals, 100 percent of HIV-positive women enrolled as part of a couple, 80 percent of HIV-negative women enrolled as individuals, and 98 percent of HIV-negative women enrolled as part of a couple shared test results with their partner six months after HIV testing.

When we disaggregated our data from 1999, we found that 64 percent of HIV-positive women who enrolled in our study as individuals, 100 percent of HIV-positive women who enrolled as part of a couple, 79.5 percent of HIV-negative women who enrolled as individuals, and 100 percent of HIVnegative women enrolled as part of a couple shared test results with their partners. This indicates a substantial change in disclosure rates over time among HIV-positive women who seek VCT services individually.

Although it is impossible to identify any single explanation for the dramatic increase in disclosure (from 27 percent to 64 percent) among HIV-positive women who enrolled as individuals, the following factors may be relevant:

- Increase in awareness and acceptability of HIV in the community and, as a result, possibly less fear about disclosure.

- Increased communication between couples about HIV and HIV testing as a result of increased awareness.

- Greater emphasis on disclosure by counselors during pretest and posttest counseling sessions.

\section{Barriers to sharing test results with partners}

Although the increase in disclosure rates is encouraging, the decision to disclose remains a difficult one for many women, as illustrated by the qualitative data from Phase 1. The major barrier to HIV serostatus disclosure to sexual partners mentioned by women surveyed in Phase 2 was fear of a partner's reaction. Fifty-two percent of women who did not share test results with their partners reported that they were afraid of how their partners would react. This fear of a partner reaction may be driven by a prior history of violence. A larger proportion of women who had not disclosed to their partners reported a history of partner violence compared to women who did share test results (42 percent vs. 33 percent, $p=.268$ ). While this difference is not statistically significant it is large enough to warrant studies with larger numbers of women.

Another related barrier to disclosure among women was lack of communication with their partners about HIV testing. Based on the survey data we found that the disclosure rate was significantly higher for couples who discussed HIV testing prior to coming to the MHIC: 94.6 percent of women who told their partners they were going to be tested disclosed their HIV results to their partners within three months after testing, compared to only 44 percent of women who did not tell their partners that they were going to be tested $(p=.000)$. 


\section{Disclosure experiences of women who shared results with their partners}

The majority of women who shared HIV test results reported that their partners showed support and understanding (74.8 percent). However, as shown in Figure 1, the proportion of women who reported this positive reaction was significantly greater among HIV-negative women, compared to HIV-positive women. HIV-positive women were significantly more likely than HIV-negative women to report that their partners panicked or felt sad. Only a small percentage of women's male partners, regardless of the women's serostatus, said that they would come for HIV testing.

Twelve women (6.4 percent) reported one or more negative responses by a partner after disclosing their test results. This included being blamed for the results or for getting tested (two HIV-negative women and eight HIV-positive women), physically assaulted (one HIV-negative woman and two HIV-positive women), and/or told to leave the house or abandoned (one HIV-negative woman and three HIV-positive women).

Figure 1 Most frequent responses by male partners to disclosure of test results

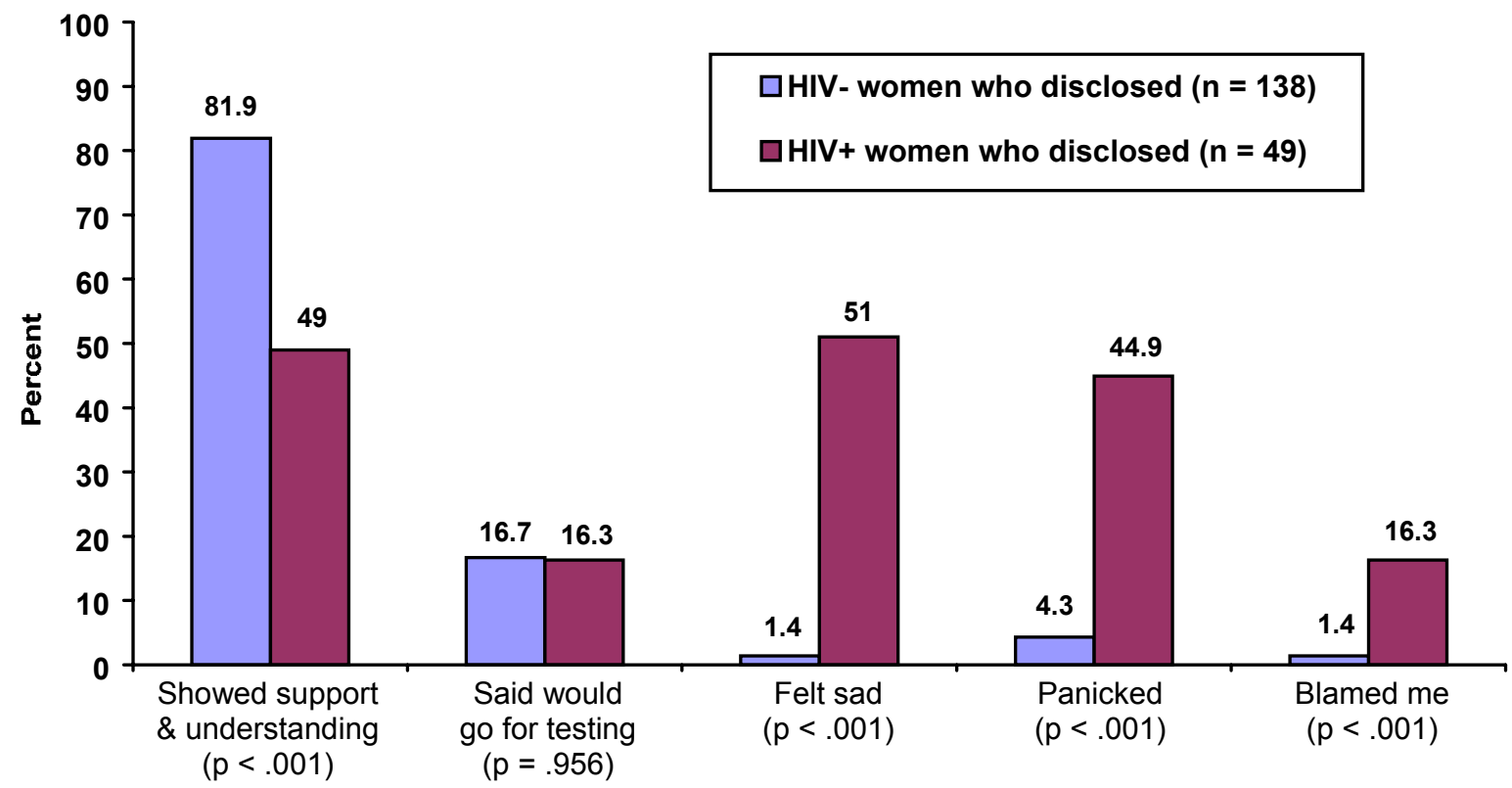

We also examined the prevalence of partner violence in the three-month period after getting tested. Women who disclosed their serostatus to their partners were less likely to report partner violence (10 percent) than women who did not disclose (17 percent).

The results of this study provide little evidence to support the hypothesis that serostatus disclosure per se leads to an increase in physical violence against women. However, for the small proportion of women who do experience negative outcomes of serostatus disclosure, these outcomes can be quite severe. 


\section{HIV and Violence Against Women}

\section{Definition and norms related to violence}

The six Kiswahili terms used to describe violence illustrate the distinction between the occurrence of violence in public rather than in private and the gender-specific nature of certain forms of violence. The term fujo is associated with general chaos or disorder and implies community-level violence. This type of chaos occurs in public spaces and, according to informants, is often perpetrated by men. Kudhalilishwa, a term that comes close in meaning to the English word insult, is often perpetrated by women. The use of insults is particularly egregious when it occurs in public, where other people can overhear them. Ugomvi wa ndani, a phrase that refers to violence that occurs in the home, is violence that is perpetrated by both men and women. According to a few informants, when this form of violence is practiced by women it implies a refusal to participate in sex. Kupigana is a term that in English means physical violence. Informants described it as an argument that crosses a certain threshold, with physical violence used to try to resolve the conflict. Kudhaliliswha rohoni translates as insults that are intended to hurt your soul. Several informants said that this implies making intimate secrets public. This is often done by women but can also be done by men. The interviews with women indicate that women express themselves aggressively to their male partners, although they are more likely to use verbal forms of aggression rather than physical forms. Women also use the refusal to perform services such as cooking and sex as a means of acting out aggressively to their partners.

\section{Private versus public spaces}

The survey data reinforced the distinction between abuse that occurs in public as opposed to private spaces. Women reported that people are more likely to intervene in disputes that occur in public than in private spaces, regardless of the perpetrator or the severity of the assault: 60.8 percent of women said that someone would intervene if a man was physically assaulting his partner in the home and there did not appear to be injuries, compared to 82.9 percent of women who said that people would intervene if the physical assault without injury occurred in a public space $(p=.000)$. If a woman appeared to sustain an injury as a result of the physical assault, 90.6 percent of women said that someone would intervene if the assault occurred in the home compared to 98 percent who said someone would intervene if the assault occurred in a public space $(p=.000)$.

\section{When is violence justified?}

Male and female informants in Phase 1 described violence as a way to "correct" or "educate" women, as illustrated by the following quotes:

Beating lightly is okay to help women correct herself. But not a beating of doing what, of hurting your partner. But you want your partner to correct herself, to see that what she has done is wrong and she isn't required to repeat it. (Male, 42 years old) 
Maybe a woman if she is very much dirty she can be beaten because it is not good.

For instance if there is a child and it is not fed as it is supposed to be you can

come to be beaten. Also, if you cook some food and you cook badly then it is a

must he beats you. (Female, 38 years old)

Violence that is considered mild or moderate and does not leave a physical mark on a woman may be justified, as is illustrated by the following comments from male informants:

I punished by beating with a cane and like three or four slaps. What I know is small, small punishments like these are normal. It is a must that I remain firm as father of the family. I am head of the household. (Male, 45 years old)

There were slaps, that is all. It is often that I have lifted a hand. She has insulted until she angers me. That is when I decide I should beat by hand. The normal beatings are acceptable, those when you beat your partner without injuring her, without putting a defect on her. (Male, 29 years old)

When we asked women under what conditions it would be appropriate for a man to physically punish his partner, 41 percent of the women identified at least one situation in which physically punishing women is justified. For example:

- 29.4 percent of women agreed or strongly agreed that punishment would be justified if a woman disobeyed her partner.

- 21.7 percent of women agreed or strongly agreed if a man found out that his partner was unfaithful to him.

- $\quad 17.6$ percent of women agreed or strongly agreed if a woman refused to have sexual relations with her partner.

- 40.4 percent of women said that a woman was not justified in denying her partner sex even after he had beat her; 16.8 percent of women felt that the fear of contracting HIV was not a valid justification for refusing sex.

\section{Scope and severity of violence}

Childhood sexual abuse: Among the 245 women surveyed, 8.5 percent reported that they had been forced by someone older to have sex or to do something sexual at least once before they were twelve years old. Of the 21 women who reported that they had experienced sexual abuse before the age of 12 , eight women were abused by a family member, five were abused by a neighbor, three were abused by a family friend, two by a male worker in the house, two by a stranger, and one by a male friend. Less than half the women who were abused as children told someone about the abuse. Among the women who did seek help, 70 percent told their mothers. See Table 4 for a comparison of violent experiences, including childhood sexual abuse, among HIV-positive and HIV-negative women. Childhood sexual abuse was not significantly associated with HIV status when controlling for potential confounders such as age, education, marital status, socioeconomic status, and duration of relationship. 
Lifetime violence by an intimate partner: Adult violence was commonly reported among women: ${ }^{4}$

- 46.5 percent had had at least one partner who had been verbally abusive and 6.1 percent had had two or more partners in their lifetime who had been verbally abusive.

- 38.5 percent of women had had at least one partner who had been physically abusive and 4.1 percent of women had had two or more partners who had been physically abusive.

- 16.7 percent of women had at least one partner who had been sexually abusive and 1.6 percent had two or more sexually abusive partners.

Among women who reported having had at least one abusive partner, 58.5 percent of women told someone about the verbal abuse, 77.7 percent told someone about the physical abuse, and 35.7 percent told someone about the sexual abuse. When controlling for other confounders the mean number of physically abusive partners for HIV-positive women was significantly higher than for HIV negative women (.61 vs. .37, OR:1.81; 95\% CI:1.19-2.76)

\footnotetext{
${ }^{4}$ To describe lifetime adult violence we asked informants to tell us how many partners they have had who have hit, slapped, kicked, pushed, shoved, or otherwise physically hurt them. We also asked women to tell us how many partners they have had who have yelled at them or called them names at least once a week and how many partners they have had who have physically forced them into sexual activity against their will. To measure violence with their current partner we adapted the Conflict-Tactic Scale for use in the Tanzanian context (Straus et al. 1996).
} 
Table 4 Frequencies of lifetime violence by HIV serostatus

\begin{tabular}{|c|c|c|c|c|c|c|}
\hline Violence Measures & $\begin{array}{l}\text { HIV- } \\
n=172\end{array}$ & $\begin{array}{l}\text { HIV+ } \\
n=73\end{array}$ & Model 1 & Model 2 & Model 3 & Model 4 \\
\hline & $\%$ & $\%$ & OR & & & \\
\hline $\begin{array}{l}\text { Sexual violence under } \\
\text { the age of } 12 \text { years }\end{array}$ & 7.6 & 11.0 & $\begin{array}{l}1.50 \\
.59-3.78\end{array}$ & $\begin{array}{l}1.66 \\
.63-5.06\end{array}$ & $\begin{array}{l}1.78 \\
.62-5.06\end{array}$ & $\begin{array}{l}1.60 \\
.56-4.58\end{array}$ \\
\hline $\begin{array}{l}\text { Physical violence } \\
\text { with current partner } \\
\text { in last } 3 \text { months }\end{array}$ & 9.3 & 16.4 & $\begin{array}{l}1.91 \\
.80-4.56\end{array}$ & $\begin{array}{l}1.67 \\
.67-4.12\end{array}$ & $\begin{array}{l}1.53 \\
.58-4.03\end{array}$ & $\begin{array}{l}1.56 \\
.59-4.13\end{array}$ \\
\hline $\begin{array}{l}\text { Physical violence ever } \\
\text { with current partner }\end{array}$ & 28.3 & 52.2 & $\begin{array}{l}2.68^{* *} \\
1.47-4.89\end{array}$ & $\begin{array}{l}2.07^{*} \\
1.10-3.90\end{array}$ & $\begin{array}{l}2.47^{* *} \\
1.24-4.96\end{array}$ & $\begin{array}{l}2.42^{* *} \\
1.20-4.87\end{array}$ \\
\hline \multirow[t]{2}{*}{$\begin{array}{l}\text { Sexual violence ever } \\
\text { with current partner }\end{array}$} & 23.0 & 44.1 & $\begin{array}{l}2.63^{* *} \\
1.39-4.98\end{array}$ & $\begin{array}{l}2.24^{*} \\
1.16-4.35\end{array}$ & $\begin{array}{l}2.30^{*} \\
1.17-4.51\end{array}$ & $\begin{array}{l}2.39^{* *} \\
1.21-4.73\end{array}$ \\
\hline & Mean & Mean & & & & \\
\hline $\begin{array}{l}\text { Number of verbally } \\
\text { abusive partners }\end{array}$ & .5116 & .6986 & $\begin{array}{l}1.36 \\
.95-1.93\end{array}$ & $\begin{array}{l}1.23 \\
.86-1.78\end{array}$ & $\begin{array}{l}1.25 \\
.85-1.83\end{array}$ & $\begin{array}{l}1.27 \\
.86-1.87\end{array}$ \\
\hline $\begin{array}{l}\text { Number of physically } \\
\text { abusive partners }\end{array}$ & .3663 & .6114 & $\begin{array}{l}1.81^{* *} \\
1.19-2.76\end{array}$ & $\begin{array}{l}1.58^{*} \\
1.02-2.44\end{array}$ & $\begin{array}{l}1.61^{*} \\
1.00-2.58\end{array}$ & $\begin{array}{l}1.65^{*} \\
1.02-2.67\end{array}$ \\
\hline $\begin{array}{l}\text { Number of sexually } \\
\text { abusive partners }\end{array}$ & .1773 & .2260 & $\begin{array}{l}1.24 \\
.71-2.18\end{array}$ & $\begin{array}{l}1.18 \\
.66-2.13\end{array}$ & $\begin{array}{l}1.27 \\
.69-2.34\end{array}$ & $\begin{array}{l}1.33 \\
.72-2.47\end{array}$ \\
\hline $\begin{array}{l}\text { Number of physically } \\
\text { violent episodes } \\
\text { w/current partner }\end{array}$ & 4.0500 & 10.5300 & $\begin{array}{l}1.02^{*} \\
1.00-1.04\end{array}$ & $\begin{array}{l}1.01 \\
1.00-1.03\end{array}$ & $\begin{array}{l}1.02^{*} \\
1.00-1.03\end{array}$ & $\begin{array}{l}1.02^{*} \\
1.00-1.04\end{array}$ \\
\hline
\end{tabular}


Violence with current partner: Many women also repeated physical violence by a current partner. Nearly a third of women reported at least one physically violent episode with a current partner before getting tested (i.e., prior to the last three months). Among women who reported at least one physically violent episode with a current partner, the median number of physically violent events reported was 7.5. The most common forms of physical violence reported by women in their current relationships included slapping (23.3 percent), twisting an arm (16.7 percent), grabbing (12.2 percent), punching (11.4 percent), kicking (9.8 percent), slamming against a wall (8.6 percent), and choking (3.9 percent).

In the last three months since getting tested for HIV, 11.4 percent of women reported at least one physically violent event with a current partner. A similar pattern of physical assault was reported among women in the last three months: slapping (5.7 percent), twisting (4.9 percent), grabbing (2.9 percent), punching (2.9 percent), kicking (2.9 percent), choking (2.9 percent), and slamming against a wall ( 2 percent). More than a fourth of all women surveyed (27.2 percent) agreed or strongly agreed with the statement, "Violence is a major problem in my life."

Severity of violence: Among women who had experienced physical violence as an adult, 10.7 percent reported that they had been injured once as a result of the violence and 11.7 percent reported that they had sustained injuries two or more times as a result of the violence. Of women who sustained an injury, 63.3 percent saw a health care provider as a result of the injury and 23.3 percent said that they thought they should have seen a health care provider because of the injury but did not. The injuries that were sustained included bruises (16 percent); continuing pain (5.3 percent); head injuries, internal injuries, or permanent disfigurement (4.9 percent); and severe bruises, broken bones, or broken teeth (2.9 percent).

\section{Predictors of violence}

In examining the association between HIV status and current partner violence in more detail, we conducted a logistic regression analysis to identify significant correlates of current partner violence. We included individual, relational, and environmental factors in the analysis (see Table $5)$.

Individual factors: Predictors of women who are likely to be in physically violent relationships were considered (Table 5).

- The likelihood of reporting violence was significantly lower among women who were not married and not living with their current partner than among women who were married or living with their partner.

- The likelihood of reporting violence among women with less than a secondary school education was five times that of women with a postsecondary school education.

- In examining the relationship between violence by a current partner and a women's serostatus without adjusting for other variables, we found that HIV-positive women were 2.68 times more likely then HIV-negative women to have experienced a violent episode perpetrated by their current partners. However, when we examined the interaction between women's age and HIV status and controlled for other variables, the likelihood of reporting violence among younger HIV-positive women (18-29 years) was ten times higher than among younger HIV-negative women. Among older women (30-55 years), there was no association between HIV serostatus and violence. The reported rate of violence among older HIV-positive women was 47.5 
percent, not significantly different from that found among older HIV-negative women (44.7 percent). Regardless of serostatus, older women were significantly more likely to report violence than younger HIV-negative women (OR:11.66 and 9.59, respectively). This suggests that the effect of HIV serostatus on women's experiences of violence is salient at younger ages. As women age, they increase their likelihood of experiencing a physically violent event with a partner, therefore HIV serostatus becomes less relevant as a determinant of violence.

We examined the individual characteristics of partners as predictors of violence. Women who reported that their partners maintain concurrent sexual relationships were five times more likely to have experienced physical violence than women who reported that their partners have never had other relationships.

Relational factors: We also considered the association between certain characteristics of relationships and current partner violence. The only variable that remained significantly associated with current partner violence when controlling for all other covariates was the age gap between partners. An interesting pattern emerged with regard to the age gap between partners. Women whose partners were 6-15 years older were significantly more likely to report violence than women who were either older than their partners or whose partners were 1-5 years or 16-23 years older than themselves.

Environmental factors: Finally, we considered the association between a woman's living environment and current partner violence. Sharing housing with other families was not found to be significantly associated with current partner violence. 
Table 5 Correlates of physical violence ever with current partner: univariate and multivariate logistic regression

\begin{tabular}{|c|c|c|c|c|c|c|c|c|}
\hline \multirow[b]{2}{*}{ Characteristic } & \multirow[b]{2}{*}{$\mathrm{n}$} & $\%$ & \multicolumn{2}{|c|}{ Unadjusted OR } & \multirow[b]{2}{*}{$p$ value } & \multicolumn{3}{|c|}{ Adjusted OR } \\
\hline & & Violence & OR & $95 \% \mathrm{CI}$ & & OR & $95 \%$ CI & $p$ value \\
\hline \multicolumn{9}{|l|}{ HIV status } \\
\hline HIV- & 172 & 28.9 & 1 & & & & & \\
\hline $\mathrm{HIV+}$ & 73 & 52.2 & 2.68 & $1.47-4.89$ & .0013 & N/A & & \\
\hline \multicolumn{9}{|l|}{ Age } \\
\hline $18-29$ & 119 & 23.4 & 1 & & & & & \\
\hline $30-55$ & 126 & 45.7 & 2.75 & $1.55-4.87$ & .0005 & N/A & & \\
\hline \multicolumn{9}{|c|}{ HIV status $X$ age interaction } \\
\hline HIV-, 18-29 & 93 & 14.6 & & & & 1.00 & & \\
\hline $\mathrm{HIV}+, 18-29$ & 26 & 58.0 & & & & 9.99 & $2.67-37.37$ & .0006 \\
\hline HIV-, 30-55 & 79 & 44.7 & & & & 11.66 & $3.06-44.45$ & .0003 \\
\hline $\mathrm{HIV}+, 30-55$ & 47 & 47.5 & & & & 9.59 & $2.69-34.15$ & .0005 \\
\hline \multicolumn{9}{|l|}{ Education (years) } \\
\hline $0-13$ & 212 & 37.9 & 4.46 & $1.29-15.41$ & .0180 & 5.15 & $1.06-25.05$ & .0423 \\
\hline $14-18$ & & 26 & 12.0 & 1 & & 1.00 & & \\
\hline \multicolumn{9}{|l|}{ Marital status } \\
\hline $\begin{array}{l}\text { Married } \\
\text { Not married/ }\end{array}$ & 110 & 49.1 & 1 & & .0000 & 1.00 & & \\
\hline $\begin{array}{l}\text { living together } \\
\text { Not married/not }\end{array}$ & 28 & 57.1 & 1.38 & $.60-3.19$ & .4478 & ns & & \\
\hline living together & 89 & 10.1 & .12 & $.05-.25$ & .0000 & .12 & $.04-.35$ & .0001 \\
\hline \multicolumn{9}{|l|}{ Partner's age } \\
\hline $18-29$ & 38 & 25.0 & 1 & & .1916 & 1.00 & & \\
\hline $30-39$ & 93 & 34.8 & 1.64 & $.69-3.88$ & .2631 & 31.00 & $.07-1.26$ & .1015 \\
\hline $40-64$ & 97 & 39.8 & 2.17 & $.93-5.07$ & .0749 & .12 & $.02-.70$ & .0185 \\
\hline \multicolumn{9}{|c|}{ Partner's other relationships } \\
\hline but in past & 101 & 32.7 & 1.36 & $.66-2.80$ & .4048 & ns & & \\
\hline Currently has & 69 & 44.9 & 2.28 & $1.07-4.87$ & .0324 & 5.09 & $1.85-13.99$ & .0016 \\
\hline \multicolumn{9}{|c|}{ Gap in age between partners (partner's age - woman's age) } \\
\hline $1-5$ & 101 & 29.7 & 1 & & .0773 & 1 & & \\
\hline $6-15$ & 108 & 42.1 & 1.72 & $.97-3.05$ & .0647 & 4.72 & $1.95-11.40$ & .0006 \\
\hline $15-23$ & 19 & 21.1 & .63 & $.19-2.06$ & .4456 & $\mathrm{~ns}$ & & \\
\hline
\end{tabular}

The univariate and multivariate logistic regression models use the sample size of $n=245$ with 18 missing because women reported no current partner at three-month follow-up visit. Backward stepwise regression ( $p=.10$ to enter and $p=.10$ to remove) was used to identify independent predictors of violence with current partner. Violence was defined as a report of at least one physically violent episode with current partner ever. The final logistic regression model contained the seven significant variables above. The variable duration of relationship was also maintained in the final model as a potential confounder. One interaction effect HIV status X woman's age was also found to be significant $(p=.0033)$ and maintained in the final model. The overall model chi-square was $p<.0000$. 


\section{Conclusion and Recommendations}

Our analysis indicates that decisions to test for HIV and to share test results with a sexual partner are made by weighing a number of different individual, relationship, and environmental factors. Men and women both perceive HIV testing as a way to plan for the future but are motivated to undergo testing by different factors. The women in our study described more barriers to HIV testing than did the men. The primary barrier to HIV testing and serostatus disclosure that women described was fear of conflict with partners. However, the women who come to the VCT site have a strong perception of risk for infection that may drive them to overcome the barriers to testing. When they do overcome the barriers, women are still left with the challenge of deciding whether or not to share their HIV test results with their partners. This study shows that women who have communicated with their partners about VCT before seeking services are significantly more likely to share their HIV test results than women who have not talked with their partners prior to HIV testing.

Overall, the disclosure rates among women enrolled in the study were high (79 percent). However, 30 percent of HIV-positive women did not share their test results with their partner, and 16.7 percent of HIV-positive women did not share their test results with anybody. The major reason for nondisclosure was fear of a partner's reaction. Most HIV-negative women who shared test results with their partners reported supportive reactions, while most HIV-infected women said that their partners were saddened or panicked by the disclosure. An important study finding was that very few women reported negative outcomes such as violence or abandonment as a result of telling a partner that they got tested for HIV and disclosing their results. Given the prevalence of violence among women in this study, there is considerable and justifiable fear of a partner's violent reaction, but little evidence that serostatus disclosure frequently leads to physical abuse and abandonment.

Interviews with both male and female VCT clients illuminated deeply embedded community norms about physical violence between partners. Almost half of all women surveyed (41 percent) identified at least one situation in which they felt that physical punishment of women is justified. Such conditions included disobedience, infidelity, refusal of sexual relations, and not performing household chores to the satisfaction of male partners. Some informants said that violence that does not leave sustained marks on women was "normal," indicating that there is a perceived threshold of acceptable violence in the community. This threshold is crossed when the woman sustains visible physical injuries. Informants also made a clear distinction between violence that occurs in the privacy of the home and violence that occurs in public. Respondents indicated that community members would be less likely to intervene in a physically or verbally aggressive altercation between partners if it occurred in the home rather than in a public place. These two findingsacceptance of "normal" violence and the reluctance of community members to intervene in domestic violence disputes- have important implications for violence prevention efforts. They indicate that the foundation of any organized violence prevention campaign must include efforts to raise community awareness and encourage critical attitudes toward domestic violence. Unless these underlying norms surrounding violence are addressed, other attempts to intervene on behalf of women will have limited impact.

A lifetime history of violence within this population of women was common. Close to one half of all women (42.6 percent) had had at least one physically abusive sexual partner in their lifetime. One third of women reported at least one physically violent event with a current partner $(32.2$ 
percent), and more than one quarter of women (27.2 percent) perceived violence to be a major problem in their lives. The prevalence of violence, while high, is comparable to what has been found in other African countries. For example, two population-based studies found that 32 percent of women in Midlands Province, Zimbabwe, and 42 percent of women in Kisii, Kenya, have ever experienced violence with a partner (Heise, Ellsberg, and Gottmoeller 1999).

The evidence from this study clearly supports the association between physical violence and HIV infection within the study population. HIV-infected women were significantly more likely to have had a physically violent partner in their lifetime and to have experienced an episode of physical and sexual violence with their current partner. When controlling for other covariates, the likelihood of reporting violence among younger $(<30$ years) HIV-positive women was ten times higher than among younger HIV-negative women.

Given the limitations of cross-sectional surveys, it is not possible to describe the specific causal pathways between violence and HIV infection through this study. Without knowing the timing of the occurrence of the physical assault or HIV infection, it is impossible to determine which factor preceded the other. However, the strong, consistently positive association between prior history of violence and HIV infection lends support to the theory that violence may play a role in women's risk for HIV infection in this population.

Earlier studies of HIV and violence have suggested different mechanisms through which violence and HIV may interact. Martin et al. (1999) found that Indian men who physically and sexually abused their wives were more likely to have had extramarital sex and experienced STD symptoms, thus placing their wives at risk of STDs, including HIV. Other investigators have suggested that women's experience with violence limits their ability to take preventive health actions, thereby placing them at risk for HIV infection and limiting their access to care and support services (Karim et al. 1995; Van der Straten et al. 1998; Wingood and DiClemente 1997; Worth 1989). The results from our qualitative analysis on the barriers to HIV testing among women provide evidence that women's ability to get tested for HIV, an important health measure, is hampered by violence and threats of violence from their partners. From our analysis we found that women describe fear of partner's reaction as being the major barrier to HIV testing. The decision to test was one that women often fought hard to defend or that they made without the consent of a partner. When consent from a partner was not sought before testing, conflict frequently arose and it was this conflict that women feared.

The imbalance of power between women and their partners is what places women at risk for violence from a male partner and limits women's ability to take preventive health measures. Status differentials between partners and lack of marital power of women have been found to be risk factors for female victims of severe violence in the United States (Fagan and Brown 1994). The significant predictors of current partner violence that emerged from this study's logistic regression analysis lend support to the idea that violence is more often experienced in relationships that are marked by an imbalance of power. In our study women who were not married and not living with their current partners were significantly less likely to experience violence. The fact that these women have not made a long-term commitment to their partner may provide them with the autonomy and leverage to leave violent relationships. It is also possible that the dynamics between partners change when the couple decides to live together. Couples who share domestic responsibilities may fall into more traditional and unequal gender roles than couples who live apart. Also, women with a higher education were substantially less likely to experience physical violence 
with their partners, which suggests that the social status, access to information, and earning capacity that comes with postsecondary education may provide women with some protection against violent partners and with more security if they choose to leave their partners.

Findings from this study suggest a number of recommendations that could reduce the barriers women face in getting tested for HIV and in disclosing their serostatus to their partners, as well as reduce levels of partner violence. These recommendations pertain to VCT services as well as to the wider community and policy environment.

\section{Encourage couple communication about HIV testing when promoting VCT.}

VCT promotion efforts should highlight the benefits of couple communication about HIV/AIDS and HIV testing. This may make it easier for couples to get tested and for individual women and men to share results with sexual partners.

\section{Train HIV counselors to ask questions about partner violence and to encourage disclosure when appropriate.}

The substantial change in disclosure rates over approximately five years at MHIC can be partially attributed to the development and refinement of counseling clients on disclosure. Despite improvements in counseling, at the time of the study counselors did not ask clients about experiences with partner violence. Counselors have an important role to play in helping clients develop safe disclosure plans, including finding out about the role violence plays in their lives. Therefore counselors need to be trained in how to ask sensitive questions about violence and use this information to foster but not force clients to disclose. Such training must be an integral part of VCT services to ensure high quality. In addition counselors must be aware of existing communitybased programs to support women living in violent relationships so that they can screen their clients and make appropriate referrals when necessary.

\section{Ensure that clients are the ones to make decisions about partner notification of test results.}

Ethical, legal, and professional debates on different strategies to inform people of their personal risk for HIV have not been conclusive. Some people advocate a provider-referral notification system, in which service providers actively notify the partners of persons who test positive for HIV with or without the consent of the individual tested. Others advocate a client-referral approach, in which counselors discuss disclosure plans with clients but leave the decision to share results with partners to the client. Advocates of the provider-referral approach argue that such programs may promote testing of undetected carriers of HIV and thus slow the spread of infection through this population; advocates of the client-referral approach argue that the involuntary disclosure of HIV status may discourage people from seeking HIV testing.

Given the high prevalence of physical violence reported among these female VCT clients, we feel strongly that involuntary disclosure of women's test results through a provider-referral system of notification will have negative consequences for women. Women in violent relationships may face 
life-threatening outcomes with involuntary disclosure of their serostatus to their partners. Overall, a provider-referral system may have a serious negative backlash on the numbers of clients who seek VCT services. A better alternative is to have counselors discuss disclosure plans with clients but to let the client decide whether to share results with a partner.

\section{Institute community-based efforts to address sexuality and violence.}

Women are often at risk for both HIV and violence because of the behavior of their sexual partners. Developing an ethic of respect among men and women for the health and wellbeing of their sexual partners needs to be the foundation of both violence prevention and HIV prevention efforts. Implementing programs that focus on changing negative norms about male and female sexuality and on conflict resolution is crucial. Policymakers often avoid these long-term efforts because it is difficult to measure their success and to find funding for long-term social change. However, if long-term issues are not dealt with, other efforts to address the problem are likely to have limited impact.

\section{Enact and enforce policies that reduce discrimination against women.}

The government of Tanzania needs to enforce international conventions that have already been ratified promoting gender equity and eliminating discrimination against women. This should go hand-in-hand with changes in legislation that can help women decide to leave violent relationships (i.e., laws pertaining to inheritance, land ownership, divorce, and child custody).

\section{Conduct further research on HIV and violence.}

The findings from this study highlight the need for more policy and operations research in order to:

- Assess client-initiated approaches to facilitating serostatus disclosure, such as the use of a third party (e.g., a counselor, friend, religious person) chosen by the client to mediate disclosure to the partner.

- Identify the pathways through which partner violence increases women's risk of HIV infection.

- Conduct community-based research to establish population-based estimates of violence against women in Tanzania.

- Conduct research similar to this study at other sites to examine the relationship between male and female clients' HIV serostatus, the rate of serostatus disclosure to partners, and the incidence of negative outcomes of serostatus disclosure.

- Evaluate community-based, HIV-prevention interventions that address the issue of partner violence in changing harmful attitudes and norms about sexuality and violence. 


\section{References}

Annas, G.J. 1993. "Detention of HIV-positive Haitians at Guantanamo. Human rights and medical care," New England Journal of Medicine 329(8): 589-92.

Antelman, G. et al. 1999. "Factors related to disclosure of an HIV positive test result to a sexual partner or any other confidant in Dar Es Salaam, Tanzania," paper presented at the Conference on Global Strategies for Prevention of HIV Transmission for Mothers to Infants, Montreal, Canada.

Bernard, H. Russel. 1995. Research Methods in Anthropology: Qualitative and Quantitative Approaches. Altamira Press: Walnut Creek.

Choi, K.H. et al. 1998. "Sexual harassment, sexual coercion and HIV risk among U.S. adults 1849 years," AIDS and Behavior 2(1): 33-40.

de Zoysa, I. et al. 1995. "Role of HIV counseling and testing in changing risk behavior in developing countries," AIDS 9 (suppl A): S95-101.

Earickson, R.J. 1990. "International behavioral responses to a health hazard: AIDS," Social Science and Medicine 31(9): 951-962.

Fagan, J.; Browne, A. 1994. Violence Between Spouses and Intimates: Physical Aggression Between Women and Men in Intimate Relationships. In: Understanding and Preventing Violence, Vol. 3. A. Reiss and J. Roth (eds). National Academy Press: Washington, D.C.

Gielen, A.C. et al. 1997. "Women's disclosure of HIV status: experiences of mistreatment and violence in an urban setting," Women Health 25(3): 19-31.

Gupta, G.R. and E. Weiss. 1993. "Women's lives and sex: Implications for AIDS prevention," Culture, Medicine and Psychiatry 17: 351-369.

Handwerker, P. 1993. "Gender power differences between parents and high-risk sexual behavior by their children: AIDS/STD risk factors extend to a prior generation," Journal of Women's Health 2(3): 301-316.

He, H. et al. 1998. "Violence and HIV sexual risk behaviors among female sex partners of male drug users," Women and Health 27 (1/2): 161-175.

Heise, L., M. Ellsberg, and M. Gottmoeller. 1999. "Ending violence against women,” Population Reports, Series L, No. 11. Baltimore, Johns Hopkins University School of Public Health, Population Information Program.

Jinich, S. et al. 1998. "Childhood sexual abuse and HIV-risk taking behavior among gay and bisexual men," AIDS and Behavior 2(1): 41-51. 
Kamenga, M et al. 1991. "Evidence of marked sexual behavior change associated with low HIV-1 seroconversion in 149 married couples with discordant HIV-1 serostatus: Experience at an HIV counseling center in Zaire," AIDS 5(1): 61-67.

Karim, Q. et al. 1995. "Reducing the risk of HIV infection among South African sex workers: Socioeconomic and gender barriers," American Journal of Public Health, 85(11): 15211525.

Killewo, C. et al. 1999. "HIV testing of pregnant women in sub-Saharan Africa: The PETRA experience in Dar Es Salaam, Tanzania," Poster Presentation at XIth International Conference on AIDS and STDs in Africa, Lusaka, Zambia.

Maman, S. et al. 2000. "The intersections of HIV and violence: Directions for future research and interventions," Social Science and Medicine 50 (4): 459-478.

Martin, S.L. et al. 1999. "Sexual behaviors and reproductive health outcomes." JAMA 282(20): 1967-1972.

Miles, M.B.; Huberman, A.M. 1994. An Expanded Sourcebook, Qualitative Data Analysis, Second Edition. Sage Publications: Thousand Oaks.

Pelzer, K., Hira, S., Wadhawan, D., \& Kamanga, J. 1989. "Psychosocial counseling of patients infected with HIV in Lusaka, Zambia." Community Health, 19, 164-168.

Rothenberg, K. et al. 1995. "Domestic violence and partner notification: Implications for treatment and counseling of women with HIV," Journal of American Medical Women's Association 50: 87-93.

Santana, S.; Faas, L.; Wald, K. 1991. "Human immunodeficiency virus in Cuba: The public health response of a third world country." International Journal of Health Services. 21(3): 511-537.

Straus, M. et al. 1996. "The revised conflict tactic scales (CTS2): Development and preliminary psychometric data," Journal of Family Issues 17(3): 283-316.

Temmerman, M. et al. 1995. "The right not to know HIV test results," The Lancet 345: 969-970.

The Voluntary HIV-1 Counseling and Testing Efficacy Study Group. 2000. "Efficacy of Voluntary HIV-1 Counseling and Testing in Individuals and Couples in Kenya, Tanzania, and Trinidad: a Randomized Trial." The Lancet. 356: 103-112.

United States Central Intelligence Agency Country Factbook. "Tanzania country profile." (www.odci.gov/cia/publications/factbook/tz.html). Accessed May 15, 2000.

Van der Straten, A. et al. 1995. "Couple communication, sexual coercion and HIV risk reduction in Kigali, Rwanda," AIDS 9(8): 935-944. 
Van der Straten, A. et al. 1998. "Sexual coercion, physical violence and HIV infection among women in steady relationships in Kigali, Rwanda," AIDS and Behavior 2(1): 61-73.

Wingood, G.M. and R. J. DiClemente. 1997. "The effects of an abusive primary partner on the condom use and sexual negotiation practices of African-American women," American Journal of Public Health 87(6): 1016-1018.

Worth, D. 1989. "Sexual decision-making and AIDS: Why condom promotion among vulnerable women is likely to fail," Studies in Family Planning 20(6): 297-307.

Zierler, S. et al. 1991. "Adult survivors of childhood sexual abuse and subsequent risk of HIV infection," American Journal of Public Health 81: 572-575.

Zierler, S., B. Witbeck, and K. Mayer. 1996. "Sexual violence against women living with or at risk for HIV infection," American Journal of Preventive Medicine 12(5): 304-309. 


\section{Hgrizons}

Horizons is a global operations research project designed to:

Identify and test potential strategies to improve HIV/AIDS prevention, care, and support programs and service delivery.

Disseminate best practices and utilize findings with a view toward scaling up successful interventions.

For more information, please contact:

Horizons Project, Communications Unit 4301 Connecticut Avenue, NW Suite 280

Washington, DC 20008 USA

Tel: 202-237-9400

Fax: 202-237-8410

Email: horizons@pcdc.org

www.popcouncil.org/horizons/horizons.html 